\title{
Comunicación visual de una emergencia sanitaria mundial: el caso de la Covid-19
}

\author{
Visual communication of a global health \\ emergency: the case of Covid-19
}

\author{
Mario Pérez-Montoro
}

Pérez-Montoro, Mario (2021). “Comunicación visual de una emergencia sanitaria mundial: el caso de la Covid-19". Anuario ThinkEPI, v. 15, e15d01.

https://doi.org/10.3145/thinkepi.2021.e15d01

Publicado en IweTe/ el 11 de enero de 2021

\section{Mario Pérez-Montoro}

https://orcid.org/0000-0003-2426-8119

Universitat de Barcelona

Facultat d'Informació i Mitjans Audiovisuals

Melcior de Palau, 140. 08014 Barcelona

perez-montoro@ub.edu

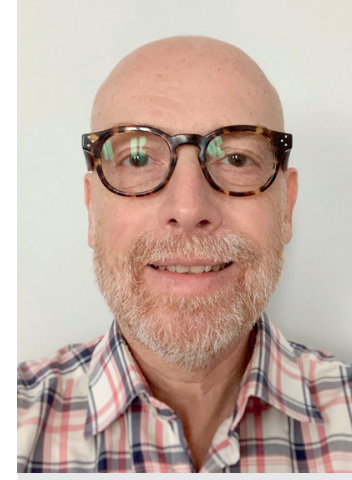

Resumen: Frente a la pandemia generada por el coronavirus, los gobiernos y los medios se encontraron de repente con el difícil reto de comunicar sobre este tema con la población y trasladar al gran público conceptos técnicos y grandes volúmenes de datos. Había que buscar una manera de hacer accesibles esos contenidos no familiares para todos, a través de fórmulas conocidas y asimilables. En ese contexto, la estrategia elegida para hacer más eficiente esa comunicación estaba clara: transmitir toda esa información vital a través de la representación visual de datos. En este trabajo analizamos los problemas asociados con los datos involucrados en esas visualizaciones y revisamos una selección de buenas y malas prácticas utilizadas en esas estrategias comunicativas.

Palabras clave: Visualización de la información; Coronavirus; Pandemia; Covid-19; SARS-CoV-2; Visualización de datos; Visualización interactiva; Infografía; Visualizaciones multimedia.

Abstract: In the pandemic generated by the coronavirus, governments and the media were suddenly faced with the difficult challenge of communicating about this issue with the population and transferring technical concepts and large volumes of data to the general public. It was necessary to find a way to make this unfamiliar content accessible to everyone, using known and assimilable formulas. In this context, the strategy chosen to make this communication more efficient was clear: transmit all this vital information through the visual representation of data. In this work we analyze the problems associated with the data involved in these visualizations and review a selection of good and bad practices used in these communication strategies.

Keywords: Information visualization; Coronavirus; Pandemic; Covid-19; SARS-CoV-2; Data visualization; Interactive Visualization; Infographics; Multimedia visualization. 


\section{Introducción}

Corrían las últimas horas de 2019. Todos nos encontrábamos organizando los preparativos para despedir el año que acababa y dar la entrada a un nuevo año. Siguiendo con la tradición y los rituales habituales, acercándose las 12 de la noche nos sentamos alrededor de un televisor para comernos las doce uvas al son de las primeras campanadas de reloj del nuevo año. Después de los besos y los abrazos, algunos pidieron, aunque fuera mentalmente, los típicos deseos que nos repetimos una y otra vez: este será mi año, aparecerá ese amor tan deseado, me inscribiré en el gimnasio y seguiré la dieta, conseguiré ese puesto de trabajo o esa promoción laboral tan anhelada...

Pero nada volvió a ser como antes. El ritual que acabábamos de hacer no surgiría efecto. El año 2020 despertaba con la llegada de unas noticias inquietantes en las que nos mostraban cómo en China construían un hospital en una semana para atender a personas afectadas por una extraña enfermedad respiratoria. Después de los típicos memes de las redes en los que se comparaba esa meteórica construcción con la "más lenta" (140 años y sin terminar) del templo de la Sagrada Familia de Barcelona (España), pudimos comprobar cómo confinaban de forma casi militar en sus casas a toda una ciudad (Wuhan, China) de más de 11 millones de habitantes para frenar el contagio de esa enfermedad. Eso ya no nos hizo tanta gracia.

Lo que vino después ya todos lo sabemos y lo continuamos sufriendo. Miedo, incertidumbre $y$, en el peor de los casos, duelo por la pérdida de seres queridos. Nuestras costumbres sociales se vieron alteradas y comenzó a planear sobre nuestras cabezas una importante crisis económica de la que todavía no sabemos cómo saldremos.

\section{"La estrategia elegida para hacer más eficiente la comunicación estaba clara: transmitir toda esa información vital mediante la representación visual de datos"}

\section{Aplanemos la curva: la}

\section{visualización de información como estrategia comunicativa}

En medio de este panorama desolador, como si de el guion de una película sobre un universo distópico se tratara, se comenzó a instalar entre nosotros un neo-lenguaje nunca antes utilizado que incluía palabras que nos eran tan ajenas como: coronavirus, PCR, test de antígenos, IgG-IgM, confinamiento, tasa de contagios, desescalada, incidencia acumulada, hidroxicloroquina, ffp2, Covid-19, tasa de letalidad o SARS-CoV-2, entre otras muchas. Una importante cantidad de nuevos conceptos, instrucciones y directrices difíciles de digerir para una población no especializada.

Los gobiernos se encontraron de repente con el difícil reto de comunicar sobre este tema con sus administrados. Para atajar la pandemia, tuvieron que hacer frente a la necesidad de trasladar al gran público conceptos técnicos y grandes volúmenes de datos. Había que buscar una manera de hacer accesibles esos contenidos no familiares para todos, a través de fórmulas conocidas y asimilables. En ese contexto, la estrategia elegida para hacer más eficiente esa comunicación estaba clara: transmitir toda esa información vital mediante la representación visual de datos.

Fue tal esa apuesta, que el lema directriz de las acciones a tomar era "aplanemos la curva". Nunca antes una gráfica de líneas se había convertido en el epicentro de una campaña de comunicación. Tras el lema se escondía la necesidad de reducir el número de contagios para que los enfermos no saturaran el sistema sanitario del país. Frente a la falta de una vacuna, el objetivo era no colapsar ese sistema, no dejar sin atención a la población y evitar de esta manera una importante cantidad de muertes.

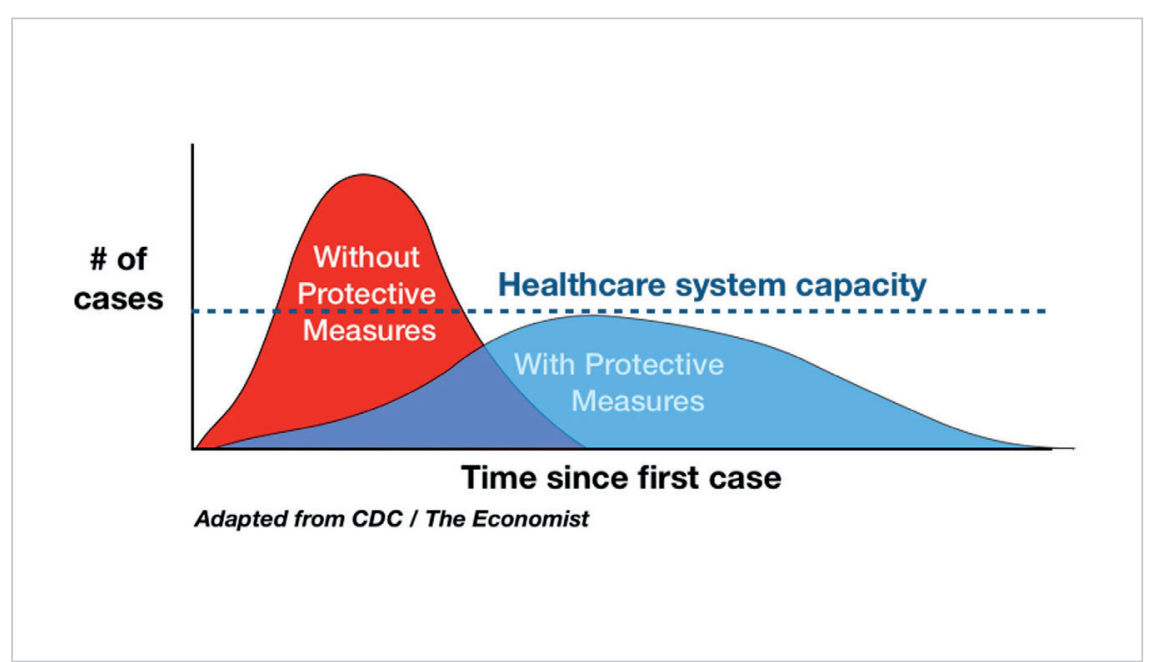

Figura 1. Gráfico de líneas incluido como cabecera en el artículo titulado "Flattening the Coronavirus curve" del periódico The New York Times (marzo 2020). https://www.nytimes.com/article/flatten-curve-coronavirus.html 
Uno de los primeros medios de comunicación que propagaron este lema fue el periódico estadounidense The New York Times. En un artículo titulado "Flattening the Coronavirus curve" $\mathrm{y}$ publicado a finales de marzo de 2020, el redactor encabezó el texto principal con un gráfico formado por dos líneas (figura 1). Una de las líneas curvas nos mostraba el elevado número de casos de contagio que se alcanzarían si no se tomaban medidas de protección. La segunda línea curva, el número de casos con las medidas aplicadas. La línea recta nos mostraba la capacidad, el límite de casos que podría admitir y asistir el sistema de salud. El pico de la línea de casos sin medidas superaba claramente esa línea recta y dejaba sin asistencia a muchos ciudadanos. El mensaje quedaba claro: debíamos aplanar la curva de la línea de contagios implantando las medidas necesarias para no tener que asumir esas dolorosas consecuencias.

Muchos medios de comunicación se hicieron eco de esta estrategia y aparecieron infinidad de productos comunicativos que incluían alguna versión de esta gráfica de líneas. Sin embargo, una de las más eficientes no provino de un medio, sino de las redes sociales. El artista digital japonés Kenta, en un tweet del 3 de abril de 2020 difundió un video donde aparecía una recreación animada en tres dimensiones de ese mismo gráfico que transmite mejor, si cabe, el mismo mensaje.

Aprovechando las 3D, el artista recrea el volumen generado por las dos líneas curvas. Esos dos volúmenes circulan en paralelo como dos trenes hacia sendos túneles que representan la capacidad del sistema sanitario. El volumen de la línea sin cuidados no cabe en el túnel y este le amputa el pico sobrante. En cambio, el volumen de la línea con cuidados entra sin problemas en el túnel de los servicios médicos (figura 2).

\section{Los datos de la pandemia: una fuente de problemas}

Pero más allá de esta versión para hacer llegar a la población el problema hospitalario, la comunicación visual de la crisis sanitaria presentó desde el inicio importantes problemas. Y una parte de esos problemas orbitaron alrededor de los datos utilizados en la visualización, en la materia de esas estrategias visuales. Si la calidad de los datos no era buena o estos eran parciales, las propuestas de representación visual como estrategia comunicativa reducían drásticamente su eficiencia.

Comencemos señalando que, desde una perspectiva conceptual, algunos autores defienden que, estrictamente hablando, no existen lo que denominamos "datos crudos" (raw data, en inglés), datos sin procesar. La expresión "datos crudos" es, en parte, un verdadero oxímoron (Bowker, 2008). Solo por el mero hecho de considerarlos datos ya no son neutros, les transferimos una carga teórica y conceptual. $Y$, en mayor o menor medida, este aspecto controvertido afloró de forma constante en el tratamiento de los datos en la pandemia.

Sin perder de vista este aspecto, el primer problema derivado que queremos destacar fue el de la recolección de datos. Durante mucho tiempo los gobiernos se enfrentaron al difícil problema de recabar los datos sobre la pandemia para poder tomar medidas a partir de los mismos. En los primeros meses, frente a la carencia de test PCR y de antígenos, fue difícil recolectar el número real de infectados y asintomáticos afectados por el virus. Y de calcular, por tanto, las tasas (como la de incidencia o la de propagación) derivadas de estos números. Lamentablemente, el único dato que se podía considerar más fiable era el de los muertos. Aunque a algunos de los fallecidos por la pandemia no se les pudo
"Los problemas en la recolección de los datos impedían adivinar, entre otras cosas, la evolución real de la pandemia o el efecto de las medidas que se iban tomando para paliarla" 
hacer el test y no fueran incluidos en esas listas. Estos problemas de recolección impedían adivinar, entre otras cosas, la evolución real de la pandemia o el efecto de las medidas que se iban tomando para paliarla.

Dejando al margen la recolección, el segundo problema destacable apareció con la propia gestión de los datos recogidos. Nunca existió una base de datos o repositorio (nacional o internacional) compartido donde administrar, registrar y compartir esos valores por los expertos responsables. Cada administración los gestionaba de forma individual y los compartía a partir de sus propios criterios, impidiendo así un análisis comparativo. Además, para agravar el problema, no se trabajó en la interoperabilidad entre esos repositorios. Esta interoperabilidad podría haber mejorado la comparación y la generación de los datos agregados con respecto a cualquier unidad política o geográfica (región, país, continente, etc.) que se quisiese analizar.

El tercer problema fue el de la actualización de esos datos. Nunca existieron criterios claros de cuándo y cómo actualizar esos valores. Algunos países o administraciones lo hacían de forma diaria. Otros de forma semanal. Algunos, incluso, por la tardanza en la obtención de los resultados de las pruebas de contagio, recogían una cifra de infectados diaria, pero que iban redondeando semanas después a partir de la recepción de los resultados de las pruebas. Esto tampoco ayudó a obtener una radiografía más cercana a la realidad para la toma eficiente de medidas.

El último de los problemas relacionados con los datos que queremos destacar fue, aunque suene ajeno al tema que estamos tratando, el político. Lamentablemente, algunos gobiernos (locales, regionales o nacionales) pudieron ver en la interferencia de esa recolección, gestión y actualización de los datos de la pandemia una posibilidad para sacar cierto rédito político y presentarse delante de sus administrados como gestores ejemplares de la emergencia sanitaria. En este trabajo no nos corresponde analizar el posible grado de intencionalidad de esas instituciones, pero entre esas acciones distorsionadoras (voluntarias o no) se pueden destacar, por ejemplo, una posible reducción del número de test para bajar así la tasa de infectados, la actualización a posteriori (incluso meses después) de los datos de la pandemia asignados a un día concreto para corregir alguna tendencia o, incluso, el retraso (o bloqueo, en algunas ocasiones) en la asignación de un código a los infectados para no hacer operativa una aplicación móvil de rastreo que venía propuesta por una instancia administrativa superior.

\section{GOV.UK Coronavirus (COVID-19) in the UK}

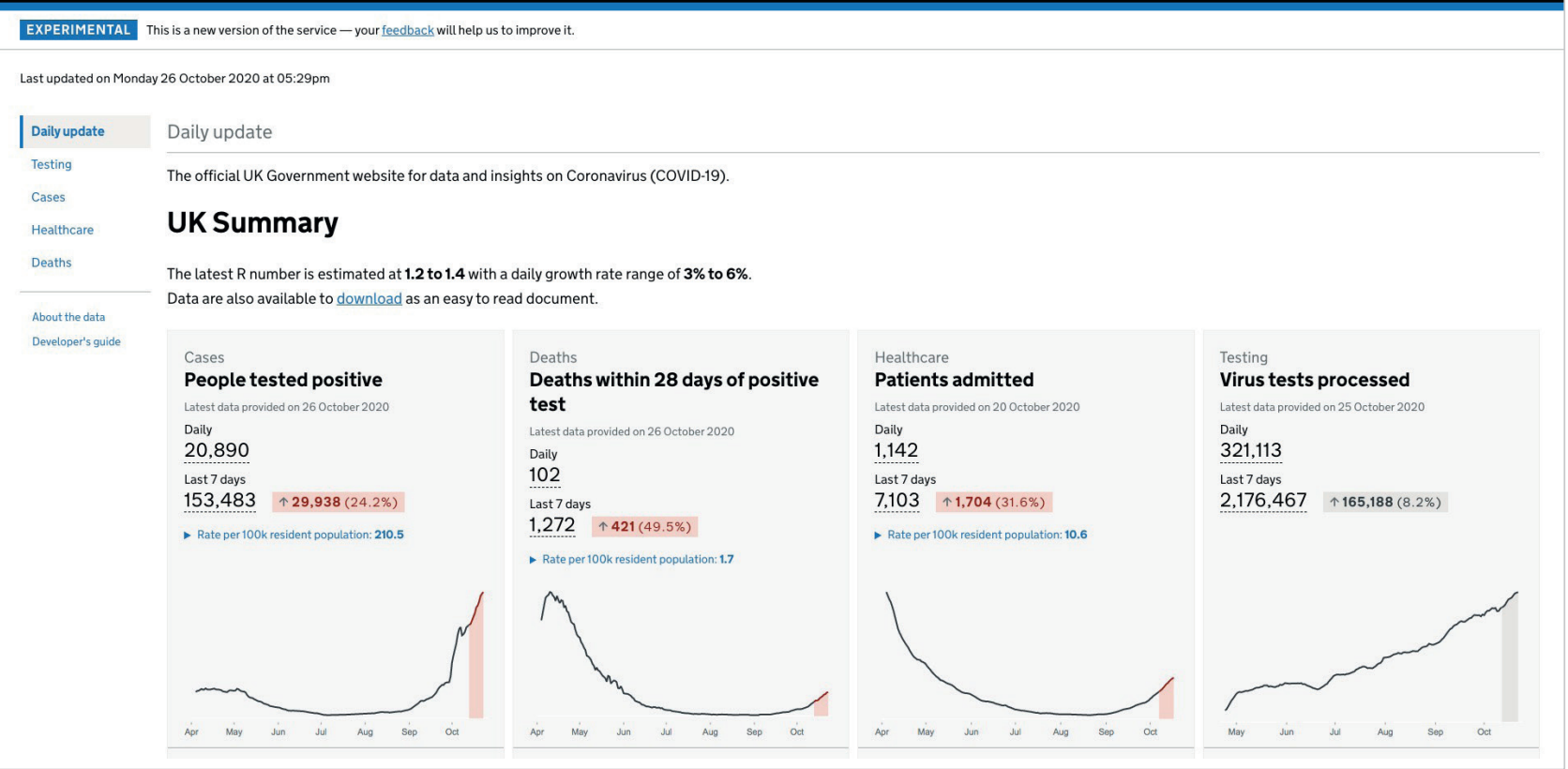

Figura 3. Recurso web del Gobierno británico donde se ofrece una consola de gráficos para visualizar los datos de la pandemia en ese país.

https://coronavirus-staging.data.gov.uk 
Sin embargo, en medio de este panorama de problemas, también se pueden identificar algunas propuestas que destacan por ser buenas iniciativas encaminadas a las recolección y gestión adecuada de los datos.

Una de estas sería la ideada por el Public Health England and NHSX del Gobierno británico (figura 3). En una web abierta, la administración británica nos ofrece una consola de gráficos limpios y simples para visualizar de forma cómoda y actualizada (indican la fecha y hora de esa actualización) los datos de la pandemia en ese país. En esa página principal se nos brinda una representación gráfica de los valores diarios de los casos, pacientes ingresados, fallecidos y test realizados, además de una caja de búsqueda para acceder a esos datos en un área concreta del país y un mapa interactivo. A partir del sistema de navegación, nos permite acceder a diferentes visualizaciones y tablas construidas con conjuntos de datos clasificados por esos temas que aparecían en la página web. En este segundo nivel, cada una de esas visualizaciones se puede explorar desagregando mediante filtros por las naciones que forman el Reino y por datos diarios o datos acumulados; además de acceder a los datos (descargables) que la conforman y obtener una información sobre esos datos y la visualización que estamos visionando.

En la misma línea, la otra propuesta que queremos destacar por su valor añadido es el recurso generado por el Center for Systems Science and Engineering de la Johns Hopkins University. En un momento en el que la epidemia comenzaba a convertirse en pandemia y no sabíamos a dónde dirigirnos para obtener y entender los datos de esa crisis sanitaria, desde este centro de investigación se comenzó a recolectar y visualizar los datos epidemiológicos mundiales, convirtiéndose en un recurso de referencia. El resultado es una consola donde podemos navegar por un mapa central de símbolos que representan mediante círculos en rojo los casos de contagiados de cada uno de los países (a mayor tamaño del círculo, mayor número de casos). Es importante remarcar que algunos investigadores se han quejado de esta visualización por la saturación visual que se crea al aparecer los datos de Estados Unidos desagregados por condado y no como un único valor. Esto provoca que se pueda entender de forma errónea que en ese país americano hay muchos más casos ya que cada círculo representa un condado, frente a la representación más simple de Europa donde cada círculo representa un país.

A la izquierda del mapa y en forma de tabla, nos permite obtener los datos de casos positivos en forma de ranquin por país, estado, provincia y ciudad. A la derecha, una primera tabla con los fallecidos

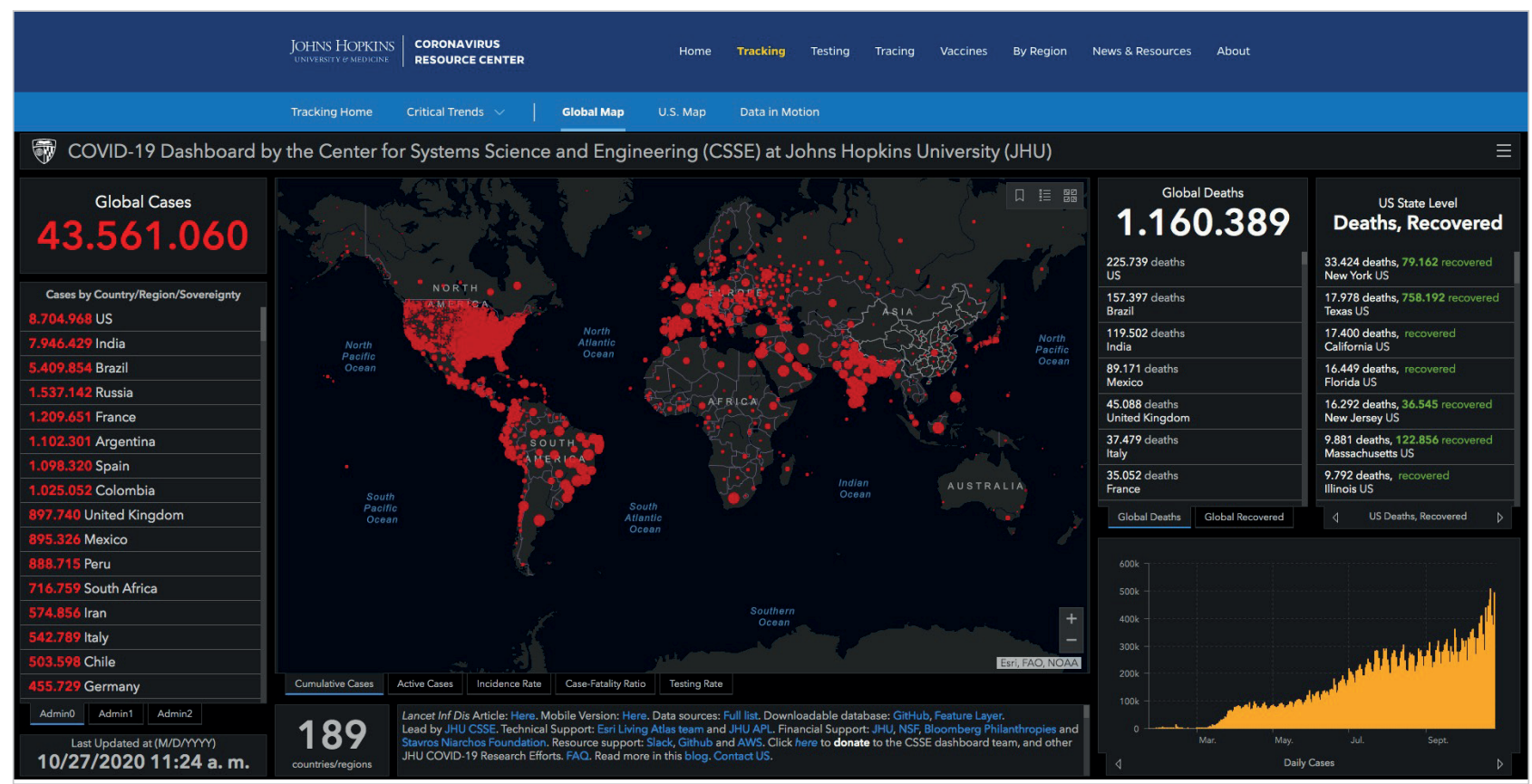

Figura 4. Recurso web de la Johns Hopkins University donde se recogen y visualizan los datos mundiales de la pandemia. https://coronavirus.jhu.edu/map.html 
y recuperados, y una segunda con esa misma información más la de los test realizados en cada uno de los estados de Estados Unidos.

\section{Buenas (y malas) propuestas comunicativas}

Dejando al margen los problemas derivados de los datos, la visualización de estos se erigió como una de las estrategias comunicativas más eficientes para informar y controlar la pandemia. La lista de propuestas comunicativas de este tipo es infinita. Algunas con mejor acierto y otras con importantes limitaciones. En este apartado vamos a seleccionar una serie de buenas prácticas relacionadas con la comunicación sobre la naturaleza del virus y su proceso de contagio, de la expansión de la enfermedad y la movilidad asociada. También señalaremos algunos ejemplos de lo que consideramos malas prácticas o visualizaciones ineficientes en este contexto temático. El trabajo terminará presentando una de las propuestas comunicativas más eficientes relacionadas con la pandemia que destaca por su eficacia e impacto comunicativo.

Comencemos con el tema de la naturaleza del virus y su proceso de contagio. Desde el principio de la pandemia, una de las primeras necesidades que tuvo la población fue conocer frente a qué virus se enfrentaba. Cubrir ese contenido informativo no era una tarea fácil ya que tenía que llegar y ser entendido por la mayoría del público, independientemente de su formación y competencia científica.

Una de las propuestas más interesantes la encontramos en el periódico español El país, en un artí-

“Una de las primeras necesidades que tuvo la población fue conocer frente a qué virus se enfrentaba. Cubrir ese contenido informativo no era una tarea fácil ya que tenía que llegar y ser entendido por la mayoría del público, independientemente de su formación y competencia científica" culo titulado "ccu cgg cgg gca. Las doce letras que cambiaron el mundo" y publicado el 11 de mayo de 2020 (Ansede; Galocha; Zafra, 2020). Este artículo, utilizando una serie de atractivas infografías y la técnica narrativa del scrollytelling y el parallax (visionado interactivo del producto a través del scroll con superposición de capas en la pantalla), nos describe de una forma inteligible el material genético del virus, su estructura física, la manera de instalarse y reproducirse en el cuerpo humano o la comparación con otros virus como el de la gripe (figura 5).

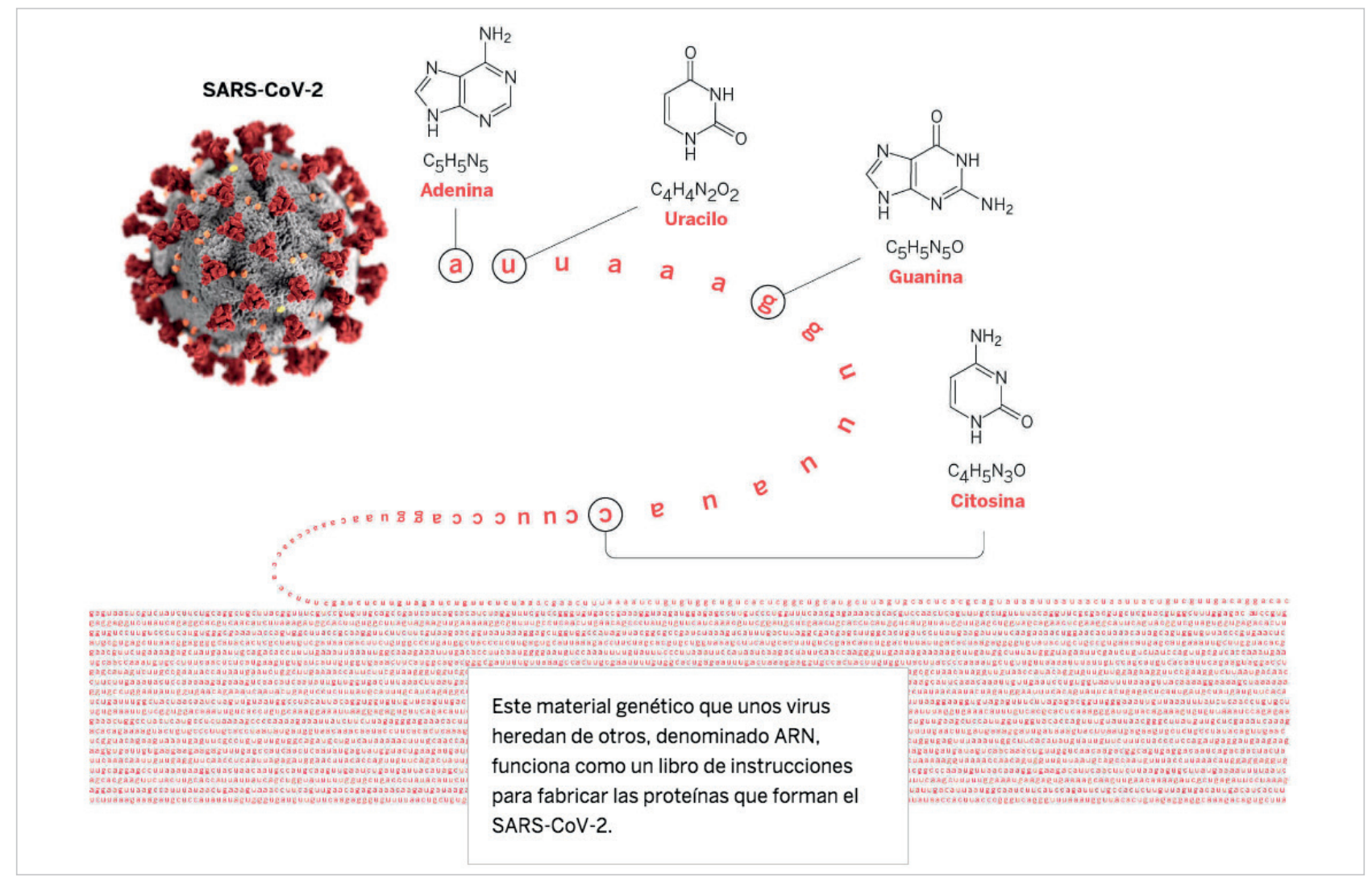

Figura 5. Artículo de El país donde se profundiza sobre la naturaleza del coronavirus.

https://elpais.com/elpais/2020/05/09/ciencia/1589059080_203445.html 


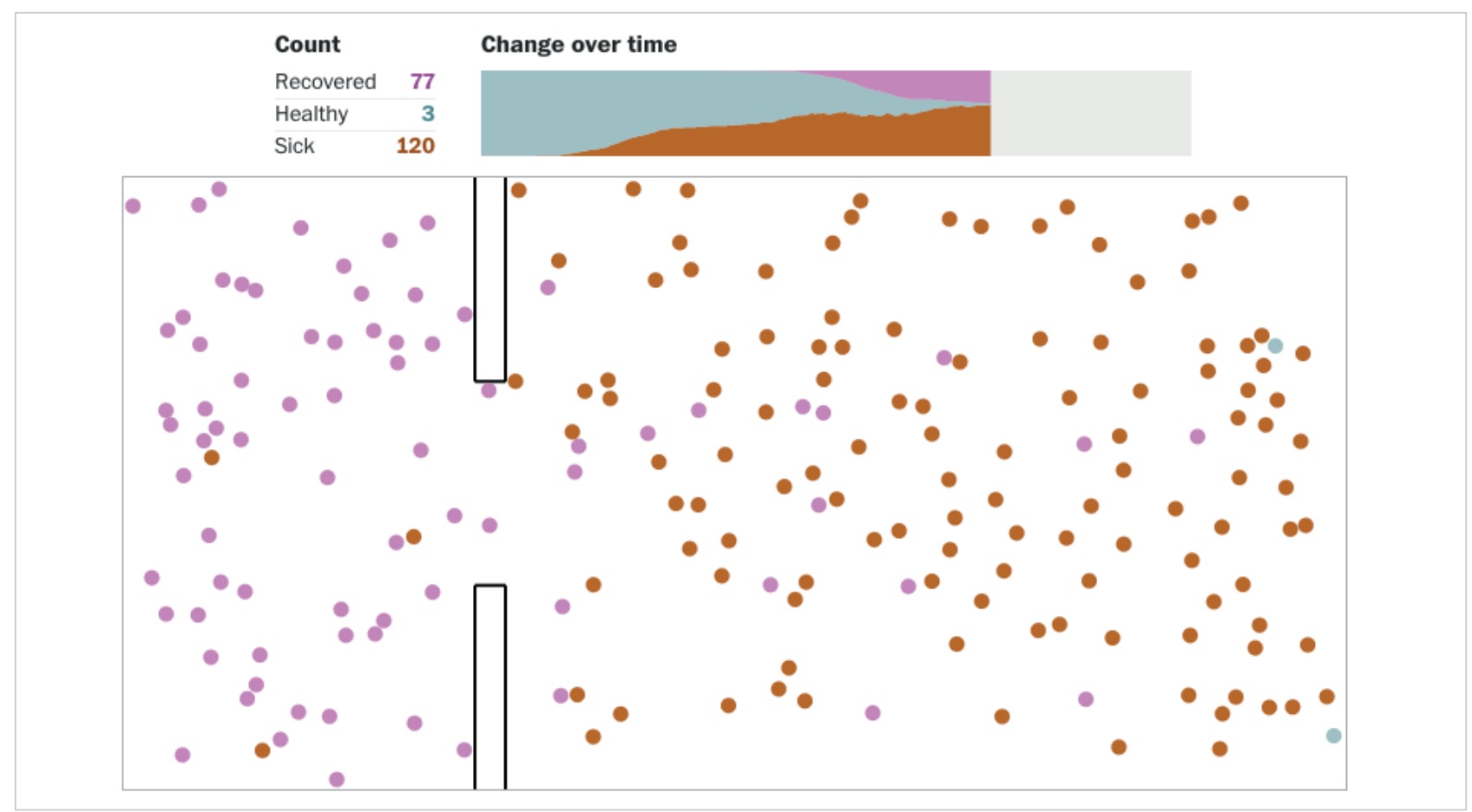

Figura 6. Artículo del Washington Post donde se aborda visualmente el tema de la velocidad de contagio por coronavirus. https://www.washingtonpost.com/graphics/2020/world/corona-simulator

Comunicar el proceso de transmisión y contagio se convirtió también en un reto informativo. El Washington Post publicó el 14 de marzo de 2020 el artículo "Why outbreaks like coronavirus spread exponentially, and how to 'flatten the curve'" (Stevens, 2020) donde explica de forma visual y mediante simulaciones la velocidad de contagio del virus y la importancia de reducir la interacción social (figura 6).

En la misma línea destacan los excelentes trabajos realizados por la agencia Reuters y por el diario El país. La sección de gráficos de Reuters, en un trabajo titulado "The Korean clusters", del 20 de marzo de 2020, ofrece un producto periodístico en el que de forma visual explica cómo se expandió un brote de infección en una iglesia y en un hospital en Corea del Sur (figura 7). Gracias a la información obtenida

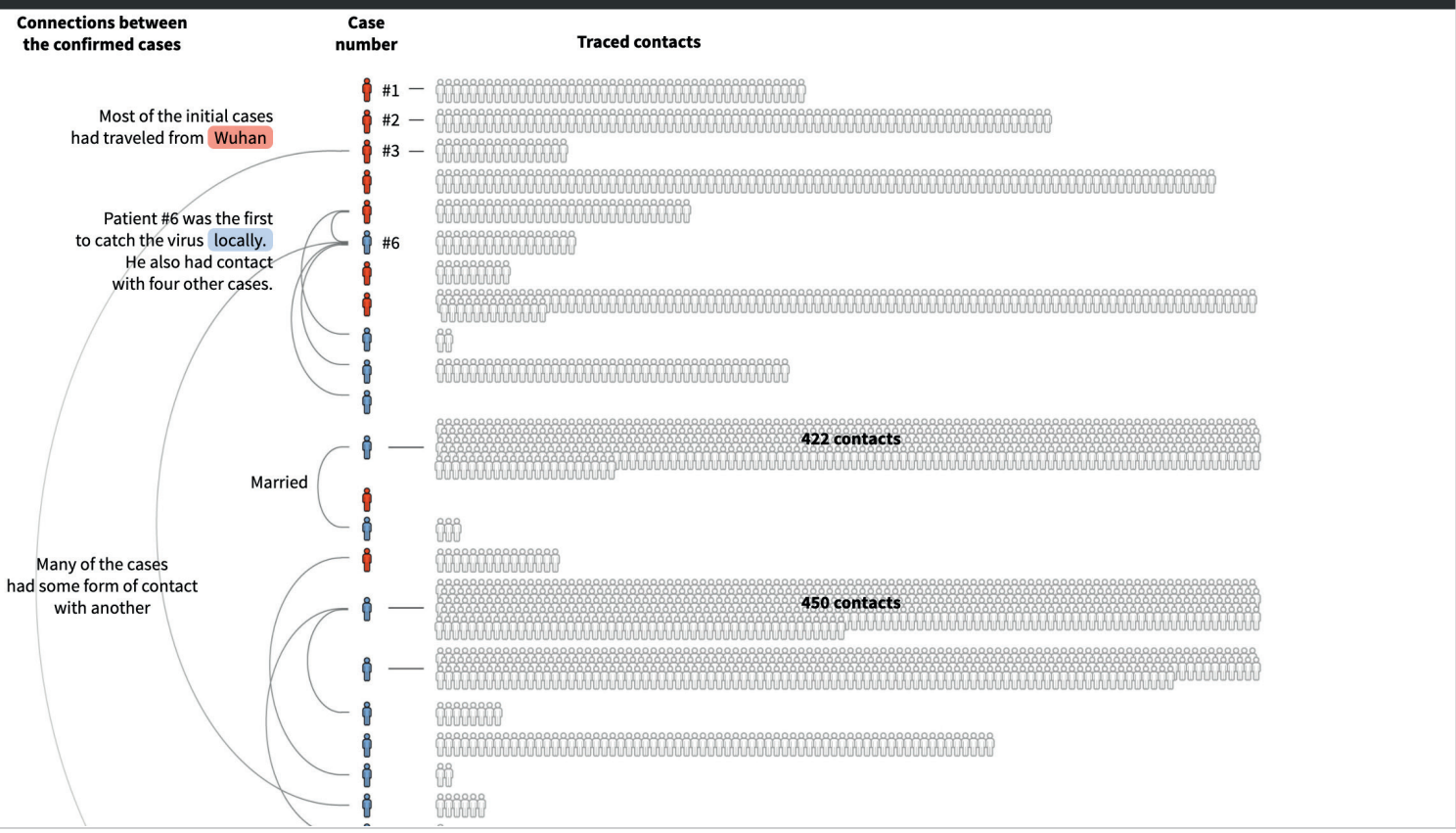

Figura 7. Análisis de la secuencia de contagios en Corea del Sur propuesto por Reuters https://graphics.reuters.com/CHINA-HEALTH-SOUTHKOREA-CLUSTERS/0100B5G33SB/index.html 
del intenso rastreo de los implicados en el brote (mediante la utilización de las tecnologías móviles), la pieza describe de forma exhaustiva la secuencia de contagios (incluidos sus parentescos e interacciones sociales) a partir de una paciente contagiada proveniente de Wuhan, China. El trabajo finaliza analizando otros brotes de contagios en la misma área geográfica.

El país, en cambio, en el trabajo "Un salón, un bar y una clase: así contagia el coronavirus en el aire" (Zafra; Salas, 2020) ofrece una exhaustiva explicación visual del papel de los aerosoles en la propagación del coronavirus. De nuevo, utilizando una serie de atractivas infografías y la técnica narrativa del scrollytelling y el parallax, la pieza nos muestra la variación de la transmisión del virus a través de los aerosoles en lugares cerrados (un salón, un bar y un aula) teniendo en cuenta tres variables: el tiempo de exposición, la calidad de la ventilación y el uso de la mascarilla (figura 8). La pieza propuesta ha sido tan bien recibida que se ha convertido en el contenido digital más visitado en la historia de la web del periódico.

Después del conocimiento sobre el virus y su transmisión, otro de los intereses informativos recayó sobre el tema de la movilidad. En este ámbito podemos destacar las propuestas visuales realizadas por las empresas Google y Apple, recabando los datos de movilidad (agregados y anonimizados, según esas compañías) asociados a los móviles que implantan sus respectivos sistemas operativos. Google, utilizando su aplicación Google Maps, ofrece los datos y un informe de movilidad de la región geográfica que elijamos. En este informe, mediante el uso de gráficos de líneas nos muestra cómo ha ido variando respecto al valor de referencia del año anterior y durante la pandemia la asistencia a las tiendas y el ocio, los supermercados y farmacias, los parques, las estaciones de transporte, los lugares de trabajo y las zonas residenciales (figura 9).

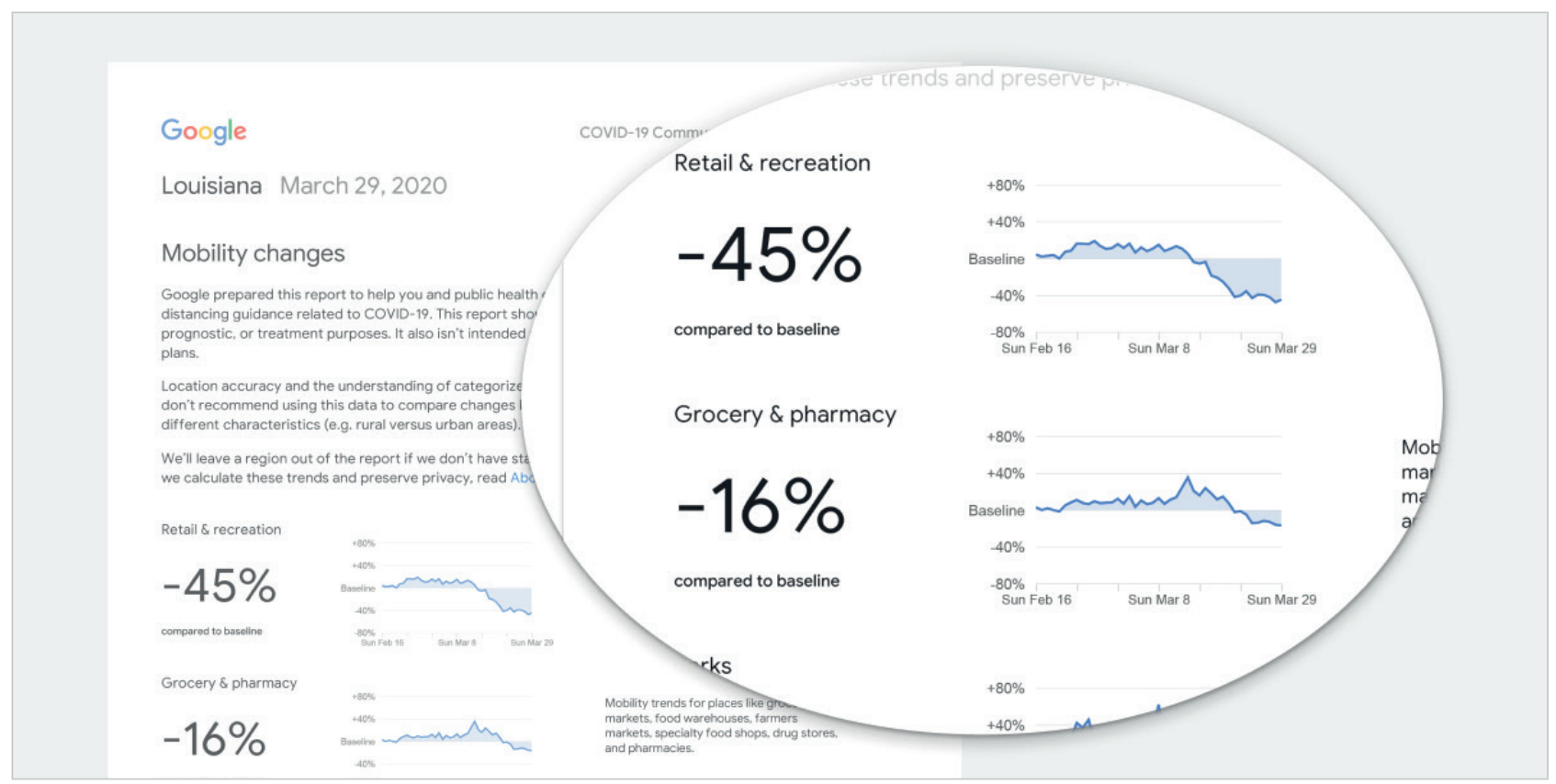

Figura 9. Informe de movilidad durante la pandemia del Estado de Luisiana ofrecido por Google https://www.google.com/covid19/mobility 


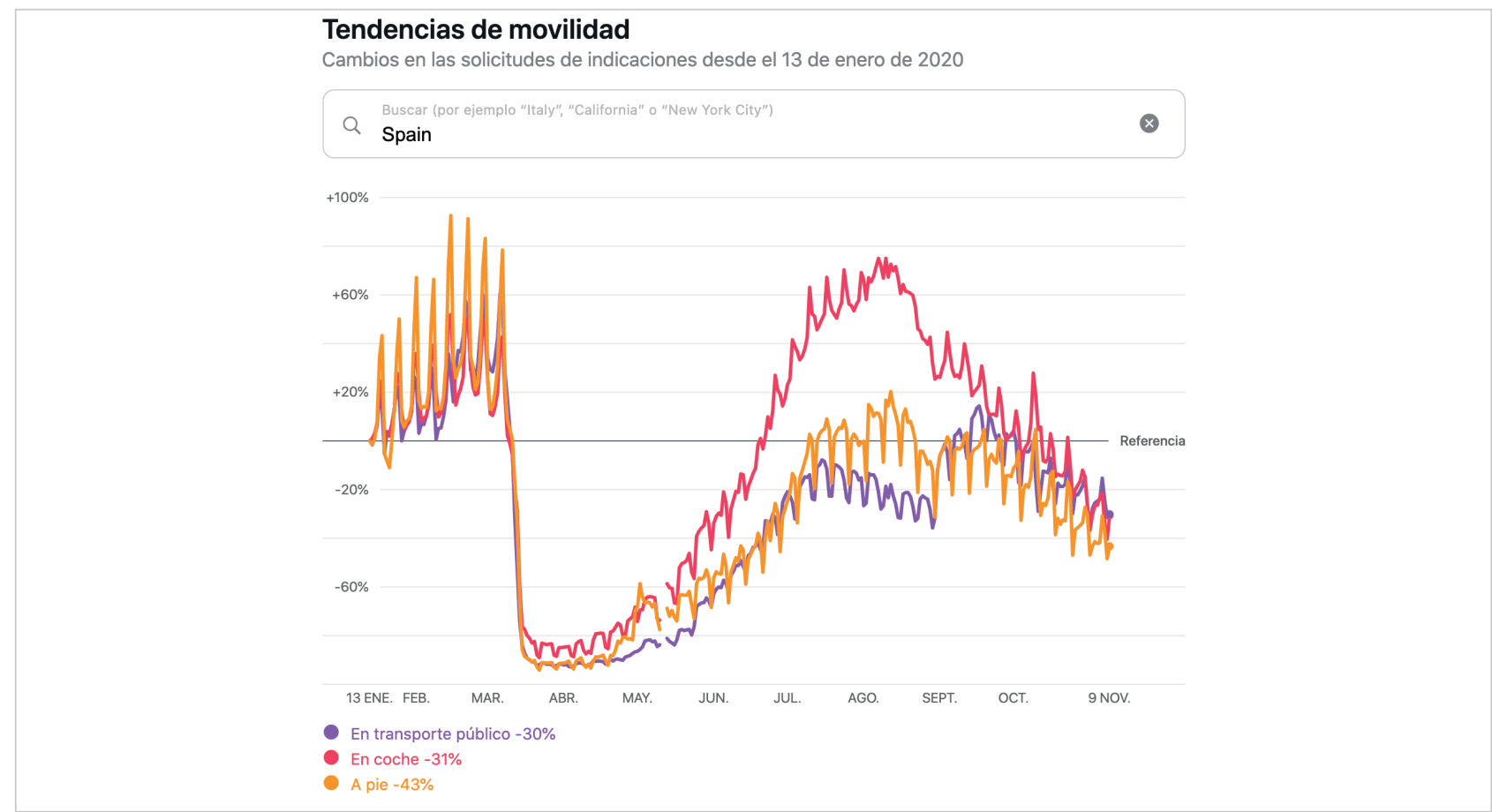

Figura 10. Informe de movilidad en España durante la pandemia ofrecido por Apple https://www.apple.com/covid19/mobility

En la misma línea, Apple, utilizando su aplicación Mapas, nos ofrece también los datos y un informe de movilidad de esa región. En este informe, mediante un gráfico de líneas muestra cómo ha ido variando durante la pandemia la movilidad en transporte público, en coche y a pie (figura 10).

Siguiendo con las buenas prácticas, queremos ahora destacar algunas piezas que se caracterizan por utilizar recursos visuales poco habituales. En este grupo, sobresalen, entre muchas otras, la utilización

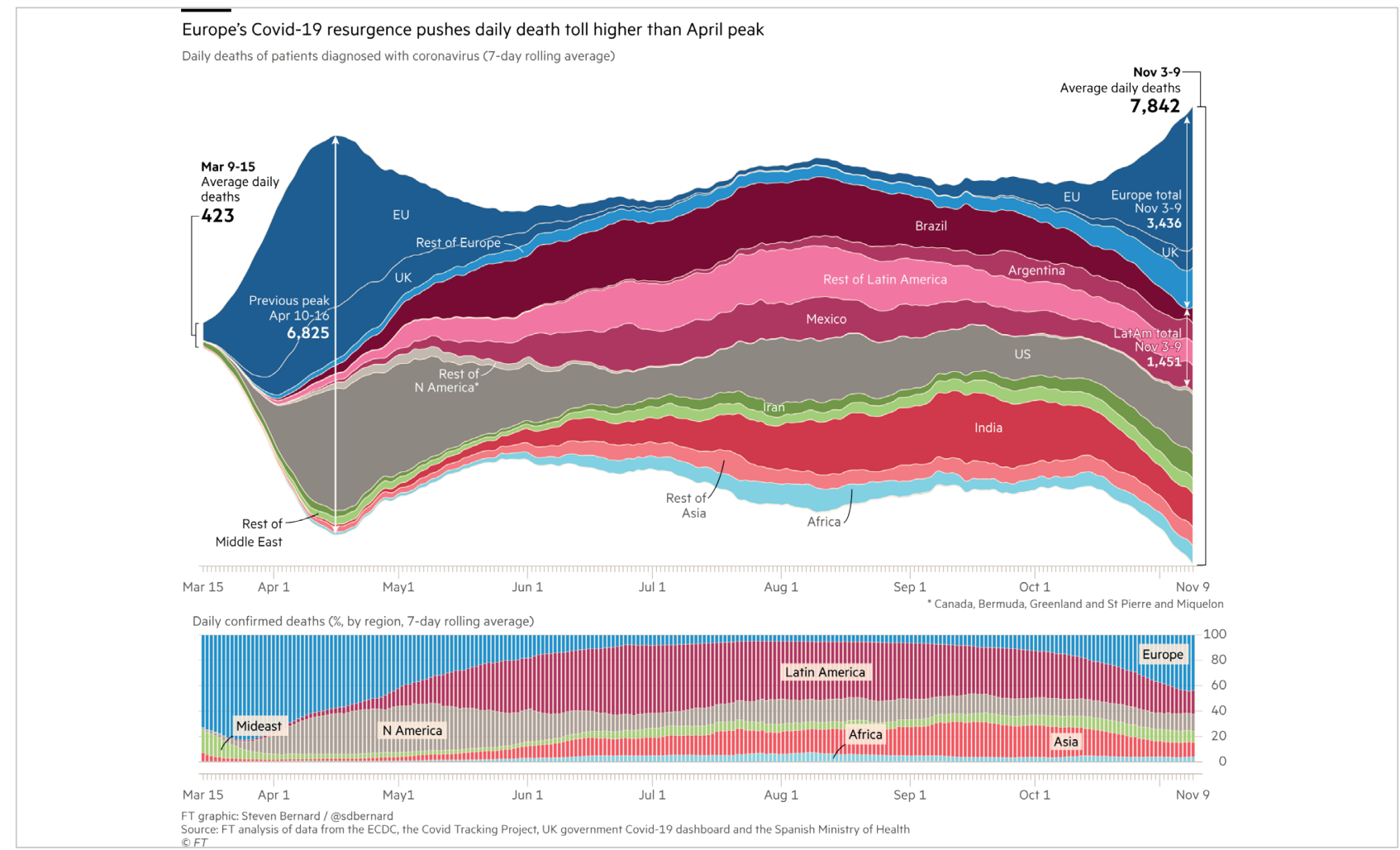

Figura 11. Evolución de muertes diarias provocada por la Covid-19 por países durante la pandemia según el Financial Times 


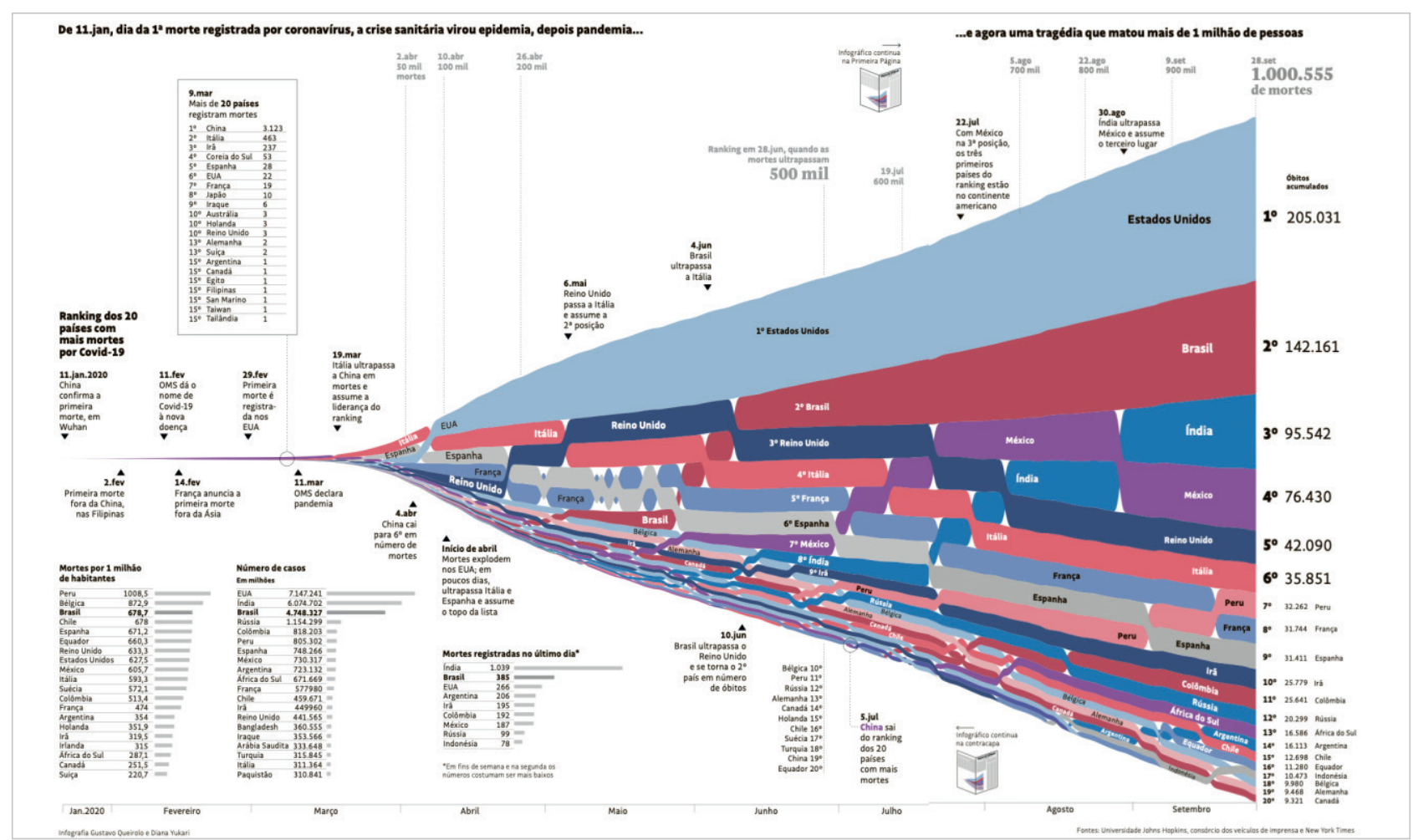

Figura 12. Evolución de muertes diarias provocada por la Covid-19 por países durante la pandemia según la Folha de Sao Paulo

https://64.media.tumb/r.com/d25c0dfd70fc1b37d18dd21b6bad8c37/57290016272081f1-c3/ s1280x1920/7e0a171159a02785ca7f0d3226874f3b65d199aa.png

de un recurso muy poco empleado: el gráfico de flujo (Stream Graph, en inglés). Es un gráfico de áreas apiladas para representar varias series temporales en forma de líneas que conforman superficies agregadas. La característica que las define es que dibujan el apilado total (no solo de una categoría, sino la suma de todas las categorías en ese punto temporal) de forma centrada sobre un punto del eje $\mathrm{X}$ (eje $X$ que se ubica sobre el punto central del eje $Y$ ). De esta manera generan un efecto visual similar al del fluir de un río para cada categoría. Dos buenos ejemplos de este tipo de gráficos lo podemos encontrar en la web del Financial Times (figura 11) y en la portada del 29 de septiembre de 2020 del periódico brasileño Folha de Sao Paulo, donde respectivamente se muestra la evolución de muertes diarias provocada por la Covid-19 por países durante la pandemia (figura 12).

Pero todo no han sido buenas prácticas en la visualización de la pandemia. Existen propuestas que por cuestiones de diseño visual pierden su eficiencia comunicativa. La lista es extensa. Destaquemos aquí alguna de estas.

La primera, ya la hemos señalado anteriormente. Como apuntamos en el apartado anterior, el recurso generado por el Center for Systems Science and Engineering de la Johns Hopkins University se convirtió en una web de referencia dónde dirigirnos para obtener y entender los datos de la crisis sanitaria. Sin despreciar ese valor, la visualización propuesta padece de cierta saturación

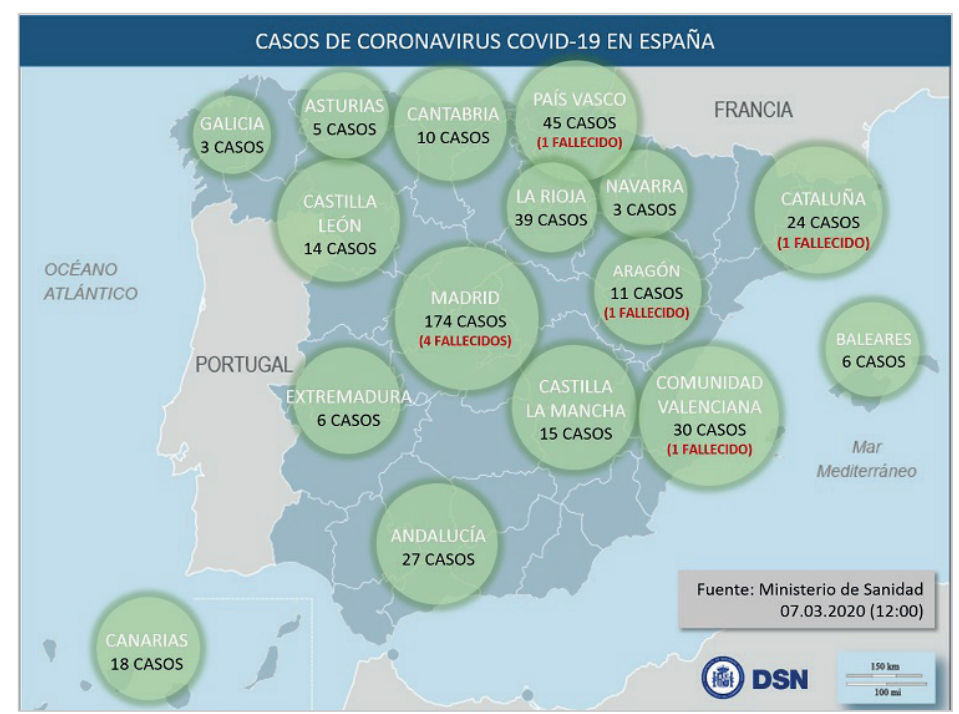

Figura 13. Mapa de símbolos graduados en el que representa el número de casos y fallecidos por coronavirus en las distintas comunidades autónomas españolas

https://www.dsn.gob.es/es/actualidad/sala-prensa/coronaviruscovid-19-07-marzo-2020 
visual que se crea al aparecer los datos de Estados Unidos desagregados por condado y no como un único valor o por estado. Como ya señalamos, esto puede dar a entender de forma errónea que en ese país americano hay muchos más casos de contagiados ya que cada círculo representa un condado, frente a la representación de Europa donde cada círculo se corresponde con un único país.

La segunda nos la ofrece el Departamento de Seguridad del Gobierno de España. En un informe sobre la situación actual publicado el 7 de marzo de 2020, este organismo incluye un mapa de símbolos graduados en el que representa el número de casos y fallecidos por coronavirus en las distintas comunidades autónomas españolas (figura 13). El problema de esta representación es el símbolo que utiliza para la codificación cuantitativa: el círculo. Dejando al margen la dificultad humana de comparar áreas, si nos fijamos en el mapa podemos ver que hay algo que no funciona. Se utilizan círculos del mismo tamaño y color (como los que se corresponden con Madrid y la Comunidad Valenciana) para representar valores cuantitativos muy alejados (174 casos y 4 fallecidos en Madrid frente a los 30 casos y un fallecido en la Comunidad Valenciana).

La tercera visualización que queremos remarcar fue creada por la web de RTVE el 13 de abril de 2020 (figura 14). Realizada con el software de visualización Flourish, en este gráfico se compara visualmente la evolución de los datos de la pandemia en Cataluña frente a los de la Comunidad de Madrid. El gráfico, en si mismo, no presenta problemas. El problema aparece cuando se visiona esa noticia en un dispositivo móvil. Al no disponer de una versión responsive que se adapte a las dimensiones de la pantalla, cuando el contenido es visionado en un dispositivo de este tipo los datos numéricos se sobreponen e impiden la lectura correcta de la visualización.

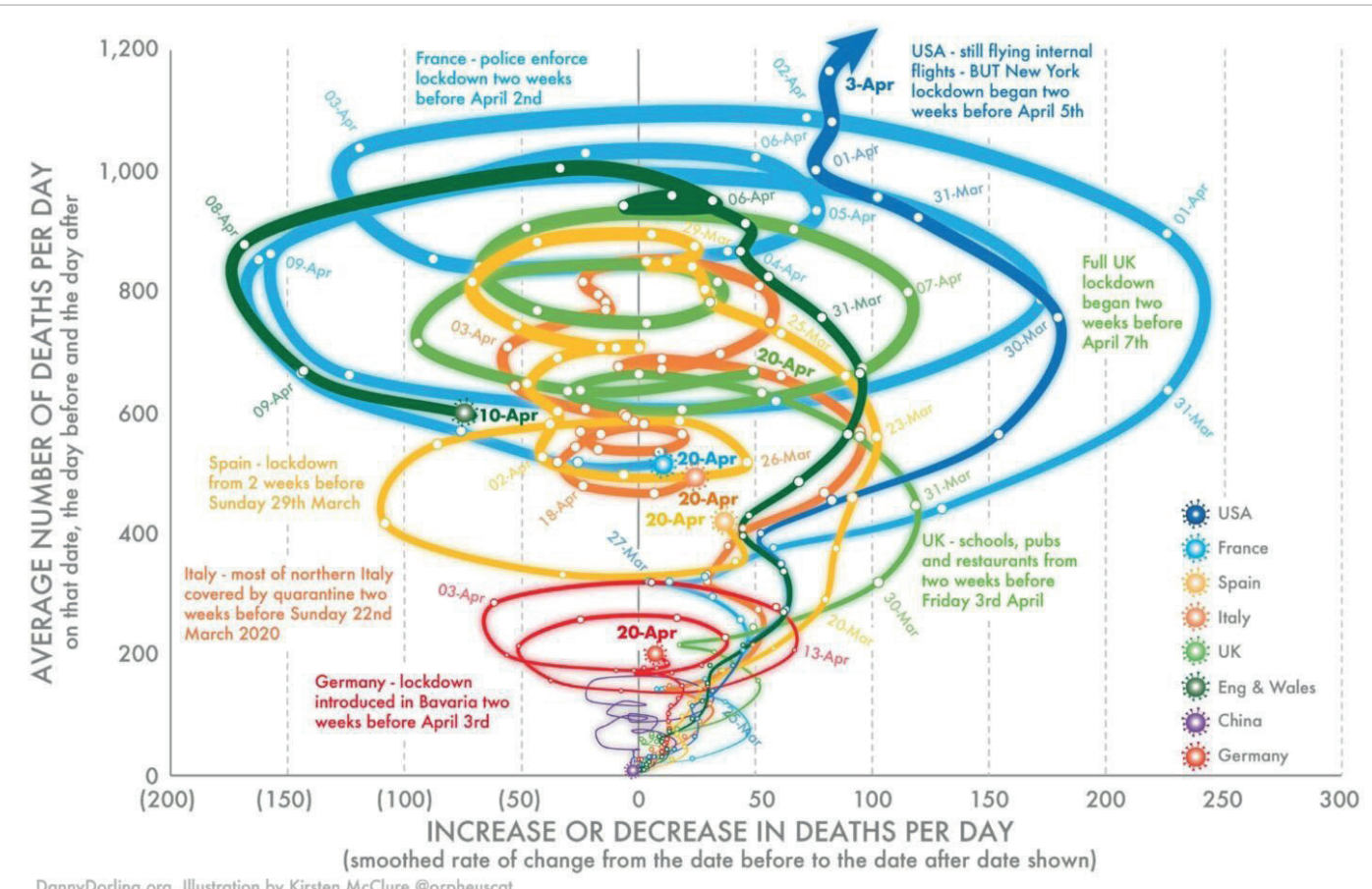

Figura 15. Representación de la evolución del número de muertes por día y de su tasa de cambio http://www.dannydorling.org/?p=7758 


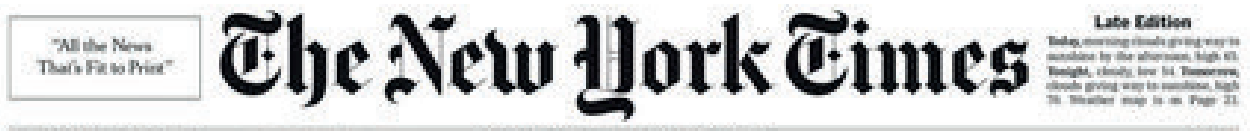

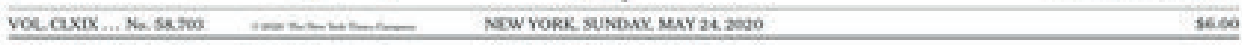

\section{U.S. DEATHS NEAR 100,000, AN INCALCULABLE LOSS}

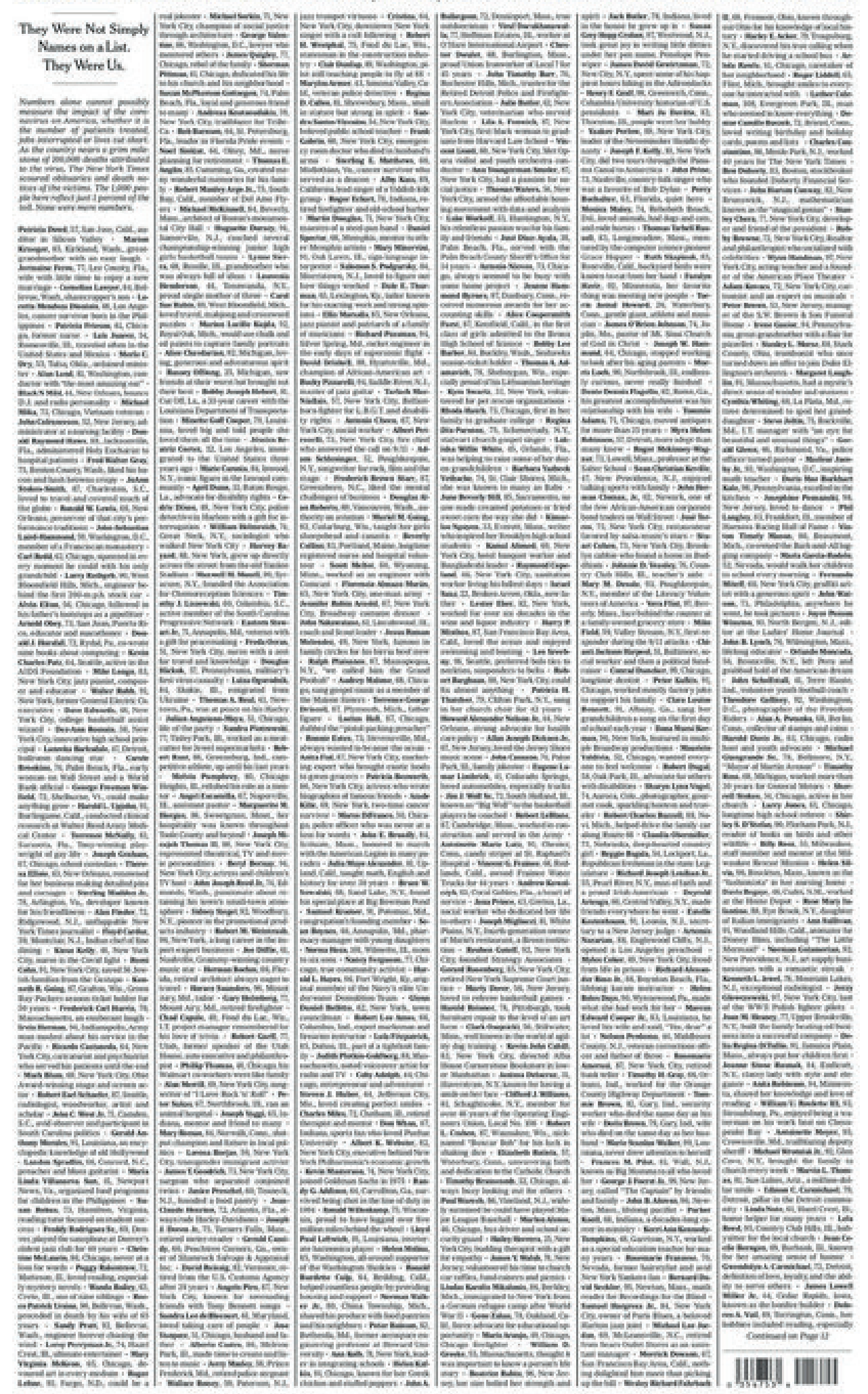

Figura 16. Portada del The New York Times del 24 de mayo de 2020 


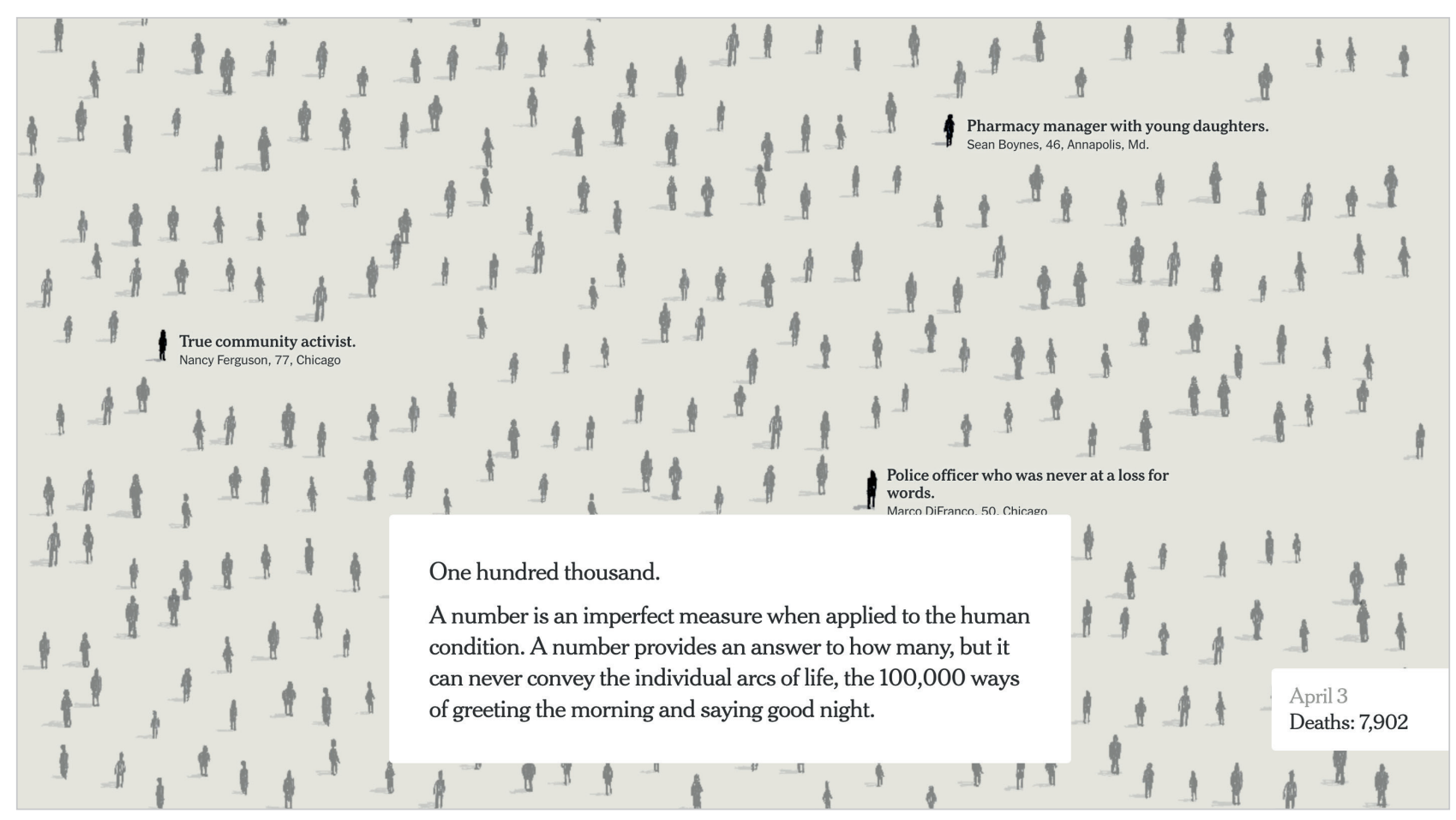

Figura 17. Pieza titulada "An incalculable loss" publicada por el The New York Times del 24 de mayo de 2020 https://www.nytimes.com/interactive/2020/05/24/us/us-coronavirus-deaths-100000.html

La última de las visualizaciones que no cumplen adecuadamente su función comunicativa que vamos a destacar nos la propone Dorling (2020), profesor catedrático de Geografía en la University of Oxford. Ayudado por la ilustradora Kirsten McClure, en su web personal ofrece una curiosa visualización (figura 15). El gráfico muestra el número de muertes por día y también la tasa de cambio en ese número. $Y$ agrega datos de siete países: Francia, EUA, España, Italia, China, Alemania y Reino Unido en su conjunto. Cuando una línea se curva hacia la derecha, las muertes por día aumentan. Cuando se curva hacia la izquierda, están disminuyendo. Los bucles indican un cambio en la tendencia.

La idea original no era mala. Sin embargo, la superposición de líneas, la sobrepoblación de texto adicional y la mala elección de una paleta de colores que no permite una discriminación visual aceptable hacen que el resultado final no comunique adecuadamente ese análisis de los datos pretendido.

No nos gustaría terminar este trabajo sin señalar una de las visualizaciones relacionadas con la pandemia que más nos ha llamado la atención por su eficacia e impacto comunicativo. No se trata de una pieza innovadora o que combine avances en visualización, sino de una estrategia clásica de representación visual.

En muchas ocasiones, cuando se ha querido conmemorar y rendir tributo a las personas que han fallecido por alguna causa común, se ha optado por incluir sus nombres en el monumento o en el acto conmemorativo. Es una manera de hacer visibles, de provocar una percepción más vívida más allá de la frialdad de las cifras, poniendo nombre y apellidos a esos muertos anónimos. Una forma de pasar de los números asépticos a las personas y sus biografías.

Y es justo eso lo que hizo el periódico estadounidense The New York Times en la portada del 24 de mayo de 2020 (figura 16). De entre los obituarios publicados en periódicos de todo el país, el rotativo seleccionó los nombres de un millar de personas como representación de todos los fallecidos por coronavirus en el país norteamericano. El resultado y el efecto es impactante. Pero todavía lo es más si visionamos su versión interactiva que lanzan en la web, donde nos muestran paulatinamente y a medida que se produjeron en el tiempo las muertes provocadas por la pandemia ofreciéndonos pequeñas reseñas biográficas sobre algunos de los fallecidos (figura 17).

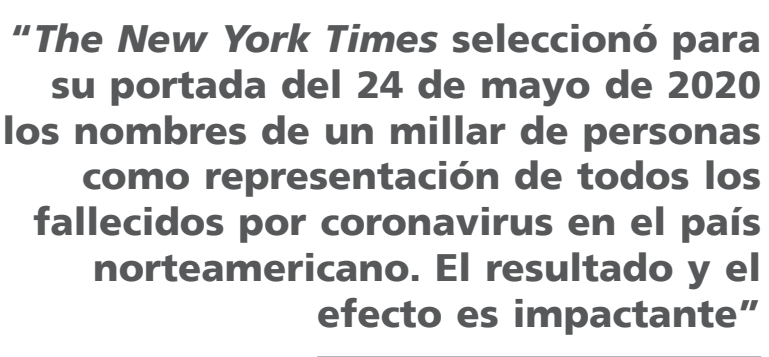




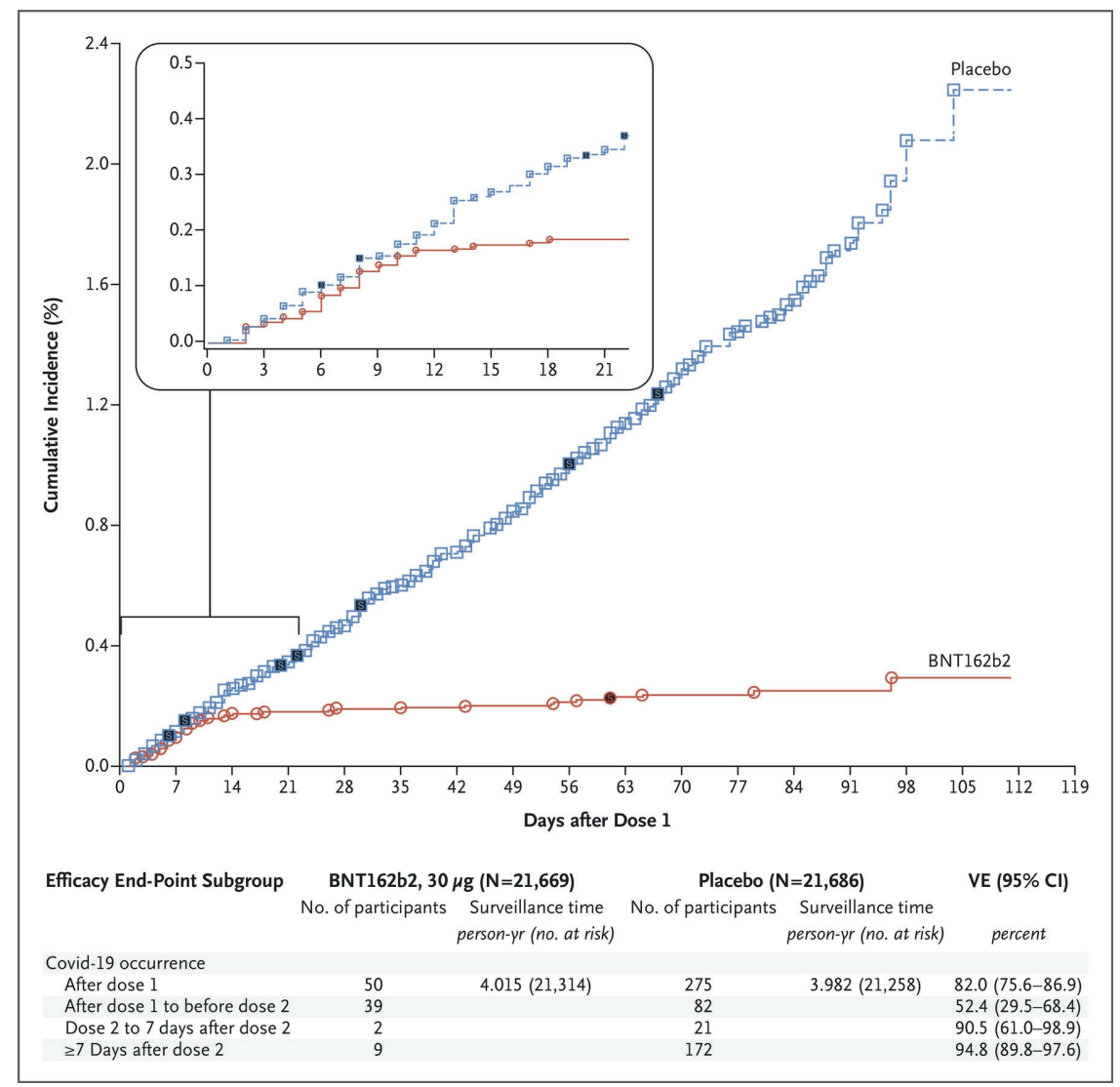

Figura 18. Gráfico incluido en un artículo de la revista The New England journal of medicine y en la que se demuestra la eficacia de la vacuna Pfizer/BioNTech https://www.nejm.org/doi/full/10.1056/NEJMoa2034577

Déjenme que termine este trabajo con un gráfico más. El que yo denominaría "el gráfico de la esperanza". Un gráfico muy simple y rudimentario que se incluye en un artículo de la prestigiosa revista The New England journal of medicine y en el que se demuestra con datos que la vacuna Pfizer/BioNTech presenta una eficacia del 95\% (figura 18). En ese trabajo, y junto a otros científicos que colaboran en la investigación, Polack (2020) muestra con dos líneas cómo van enfermando de Covid-19 a lo largo del ensayo los dos grupos de sujetos estudiados. Por un lado, los que recibieron el placebo (donde los casos crecen de forma lineal), y, por otro, el grupo de los vacunados (donde apenas lo hacen). Háganme caso: confiemos en la ciencia. ¡Acabaremos doblegando la curva!

\section{Referencias}

Ansede, Manuel; Galocha, Artur; Zafra, Mariano (2020). "ccu cgg cgg gca. Las doce letras que cambiaron el mundo". El país, 11 mayo. https://elpais.com/elpais/2020/05/09/ciencia/1589059080_203445.html

Apple (2020). Informe de movilidad en España durante la pandemia. https://www.apple.com/covid19/mobility

Bowker, Geoffrey C. (2008). Memory practices in the Sciences. Boston: The MIT Press. ISBN: 9780262524896

Departamento de Seguridad. Gobierno de España (2020). "Coronavirus (Covid-19) - 07 de marzo 2020". Departamento de Seguridad Nacional, 7 marzo.

https://www.dsn.gob.es/es/actualidad/sala-prensa/coronavirus-covid-19-07-marzo-2020

Dorling, Danny (2020). "Three charts that show where the coronavirus death rate is heading". Danny Dorling. http://www.dannydorling.org/?p=7758

Financial times (2020). "Coronavirus tracker: the latest figures as countries fight Covid-19 resurgence". Financial times, January 12.

https://www.ft.com/content/a2901 ce8-5eb7-4633-b89c-cbdf5b386938

Folha de Sao Paulo (2020).

https://64.media.tumb/r.com/d25c0dfd70fc1b37d18dd21b6bad8c37/57290016272081f1-c3/ 
Google (2020). Informe de movilidad durante la pandemia del Estado de Luisiana.

https://www.google.com/covid19/mobility

GOV.UK (2020). Coronavirus (Covid-19) in the UK.

https://coronavirus-staging.data.gov.uk

Johns Hopkins University (2020). "Covid-19 dashboard by the Center for Systems Science and Engineering (CSSE) at Johns Hopkins University (JHU)". Coronavirus Resource Center.

https://coronavirus.jhu.edu/map.html

Kenta (2020). Twitter.

https://twitter.com/kntktnk/status/1246011725293318151

Polack, Fernando P.; Thomas, Stephen J.; Kitchin, Nicholas; Absalon, Judith; Gurtman, Alejandra; Lockhart, Stephen; Perez, John L.; Pérez, Gonzalo; Moreira, Edson D.; Zerbini, Cristiano; Bailey, Ruth; Swanson, Kena A. et al. (2020). "Safety and efficacy of the BNT162b2 mRNA Covid-19 vaccine". The New England journal of medicine, v. 383, pp. 2603-2615.

https://doi.org/10.1056/NEJMoa2034577

Reuters (2020). "The Korean clusters". Reuters Graphics, 20 March.

https://graphics.reuters.com/CHINA-HEALTH-SOUTHKOREA-CLUSTERS/0100B5G33SB/index.html

RTVE (2020). "Noticias". RTVE.

https://www.rtve.es/noticias

Stevens, Harry (2020). "Why outbreaks like coronavirus spread exponentially, and how to "flatten the curve"". Washington Post, March, 14.

https://www.washingtonpost.com/graphics/2020/world/corona-simulator/

The New York Times (2020). "An incalculable loss". The New York Times, 27 May.

https://www.nytimes.com/interactive/2020/05/24/us/us-coronavirus-deaths-100000.htm/

The New York Times (2020). "Flattening the Coronavirus curve". The New York Times.

https://www.nytimes.com/article/flatten-curve-coronavirus.html

The New York Times (2020). Portada del 24 de mayo de 2020.

Zafra, Mariano; Salas, Javier (2020). "Un salón, un bar y una clase: así contagia el coronavirus en el aire". El país, 28 octubre.

https://elpais.com/ciencia/2020-10-24/un-salon-un-bar-y-una-clase-asi-contagia-el-coronavirus-en-el-aire.html

\section{Si te interesan los}

\section{INDICADORES EN CIENCIA Y TECNOLOGÍA,}

y toḍos los temas relacionados con la medición de la ciencia, tales como:

Análisis de citas, Normalización de nombré e thstituciones, Impacto de la ciencia en la sociedad, Indicadorê Sociolợía de la ciencia, Pólítica

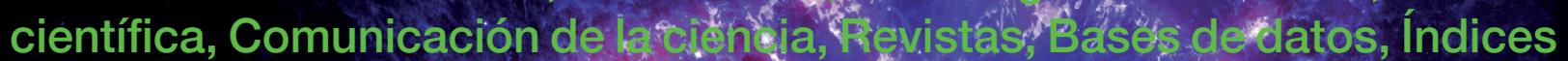
de impacto, Políticas de oben accets, fingúlisis de la núleva economía, Mujer y ciencia, etc.

Entonces ING es tu lista. Suscríbete en:

httplyww rediris.es/listlinfolincyt.html 